\title{
An experience of tunnelling in mudstone area in southwestern Taiwan
}

\author{
T.T. Wang*, T.H. Huang \\ National Taiwan University, Taipei, Taiwan, ROC
}

Received 6 February 2002; received in revised form 5 September 2002; accepted 12 September 2002

\begin{abstract}
Many tunnels will be constructed in southwestern Taiwan in the upcoming decade to meet the huge demands of transportation, energy and water infrastructure projects. Mudstone strata cover more than a $1000 \mathrm{~km}^{2}$ area, consisting mainly of massive mudstone or alternation of mudstone and sandy layer, exhibiting unfavorable geological and hydrological characteristics, making it extremely difficult for tunnelling. This paper presents the lessons learned from three tunnelling projects in the 1990s in a mudstone area. In addition to discussing the rock behavior in the vicinity of tunnel and its failure patterns, the monitoring data during tunnelling are presented as well. Finally, the effective method of design and construction are recommended for tunnelling in mudstone area.
\end{abstract}

(c) 2002 Elsevier Science Ltd. All rights reserved.

Keywords: Tunnelling; Mudstone; Water deterioration; Southwestern Taiwan

\section{Introduction}

Poorly cemented mudstone covers more than a 1000 $\mathrm{km}^{2}$ area in southwestern Taiwan. The engineering properties of this young sedimentary rock are highly sensitive to its water content and exhibit a wide range of strength and deformability. Moreover, more than 15 reservoirs located in southwestern Taiwan, the geological and hydrological conditions might cause adverse impact on civil works.

In the next decade the huge demands of transportation and the renovation of energy and water infrastructure system will be carried out in southwestern Taiwan. It is inevitable to construct numerous tunnels instead of cutting work to minimize the environmental impacts and residential resistance. Therefore, tunnelling in southwestern Taiwan is quite a challenging task due to the unfavorable engineering properties of mudstone.

This paper presents the experience from tunnelling projects in mudstone area over the past decade. In

\footnotetext{
*Corresponding author. Laboratory of Rock Mechanics, Department of Civil Engineering, National Taiwan University, 1, Section 4 , Roosevelt Road, Taipei, Taiwan. Tel.: + 886-933-757032/2-23630231x3113/314; fax: +886-2-2364-5734

E-mail address: wangseeu@ms11.hinet.net (T.T. Wang).
}

addition to discussing the geological and hydrological condition and the relevant tunnel behavior and failure patterns, the monitoring data are also accessed to establish the tunnelling concepts in mudstone area. Results from the experience can provide a valuable reference for the design and construction of tunnelling in mudstone area.

\section{Engineering properties of mudstone in southwest- ern Taiwan}

Fig. 1 illustrates the outcrops of mudstone formation in Chyai, Tainan, and Kaoshiung counties in southwestern Taiwan. The total thickness of these late Miocene to Pleistocene sedimentary rocks reaches several thousand meters. The stratigraphy is rather monotonic, consisting mainly of massive mudstone or alternation of mudstone and sandstone. Mudstone usually exhibits light alkalinity. Owing to the low resistance to weathering and unsuitability for plant growth, badland topographic expressions are commonly viewed in this area and are referred to as a 'moon-world'. Fig. 2 illustrates a typical outcrop of mudstone slope taken from the northern portal of Chungliao Tunnel in southwestern Taiwan. 


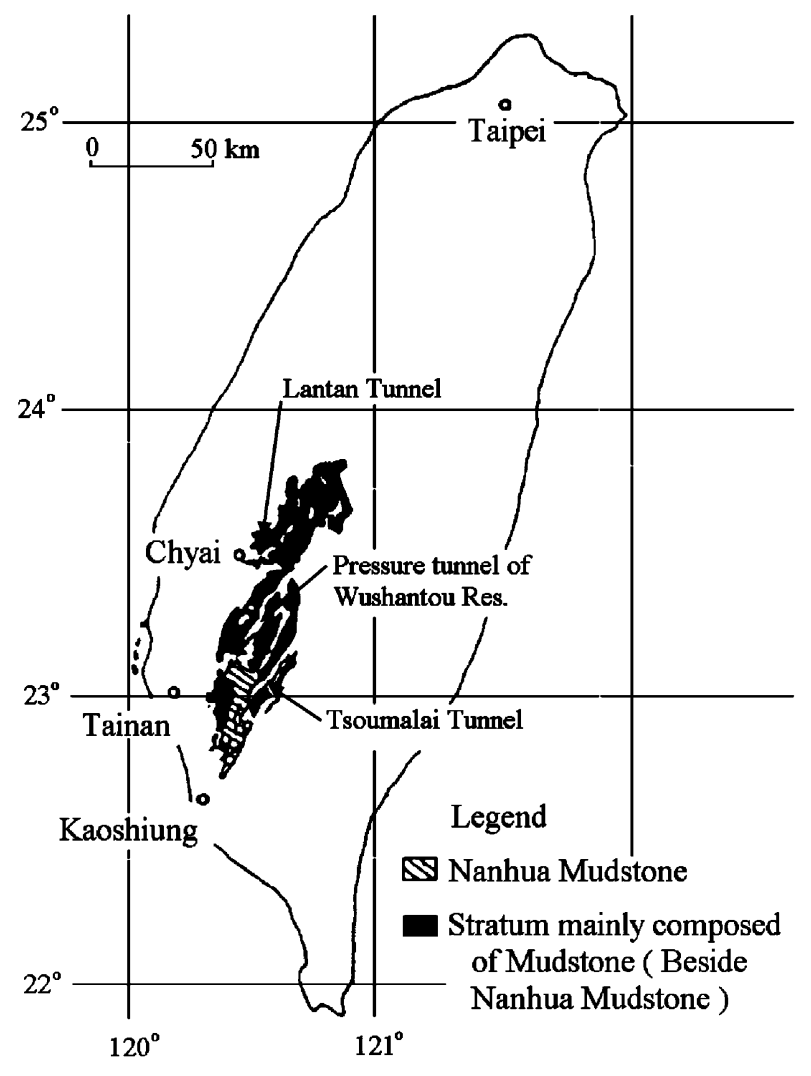

Fig. 1. The outcrops of mudstone in southwestern Taiwan and the location of tunnelling cases.
The engineering properties of mudstone are highly influenced by water. The uniaxial compressive strength of mudstone ranges from 0.2 to $8.5 \mathrm{MPa}$. Results obtained from a series of triaxial compression tests indicated that the cohesion varies from 0.06 to 0.24 $\mathrm{MPa}$ and the friction angle ranges from 10.6 to $55.0^{\circ}$, depending on its water content and weathered degree (Lee et al., 1994).

The permeability of mudstone ranges from $10^{-7}$ to $10^{-9} \mathrm{~cm} / \mathrm{s}$ and can be considered as impermeable. Even in the rain season, the rainfall can only seep into approximately $40 \mathrm{~cm}$ below the ground surface. However, the sandstone layer sometime existed in mudstone strata may be an aquifer in mudstone area and the groundwater level might be risen.

The pronounced swelling and slaking properties are other characteristics of mudstone. The intact sample of mudstone exhibits a swelling pressure ranging from 0.14 to $0.35 \mathrm{MPa}$ by preswelled method. The free swelling percentage is approximately $6-10 \%$, and the slaking speed is approximately $10 \mathrm{~kg} / \mathrm{m}^{2} / \mathrm{h}$ for the first hour immersed in water. The index of durability is approximately 9.4-97.3\% (Tasi and Chang, 1994).

In a word, mudstone is sensitive to slaking and weathering, with a high erosion rate. In addition, the strength decreases with an increase of the water content. Moreover, there are many reservoirs located and streams crossed this area. The well groundwater supply system and the heavy rainfall in Taiwan deteriorate the engineering properties of mudstone, subsequently creating

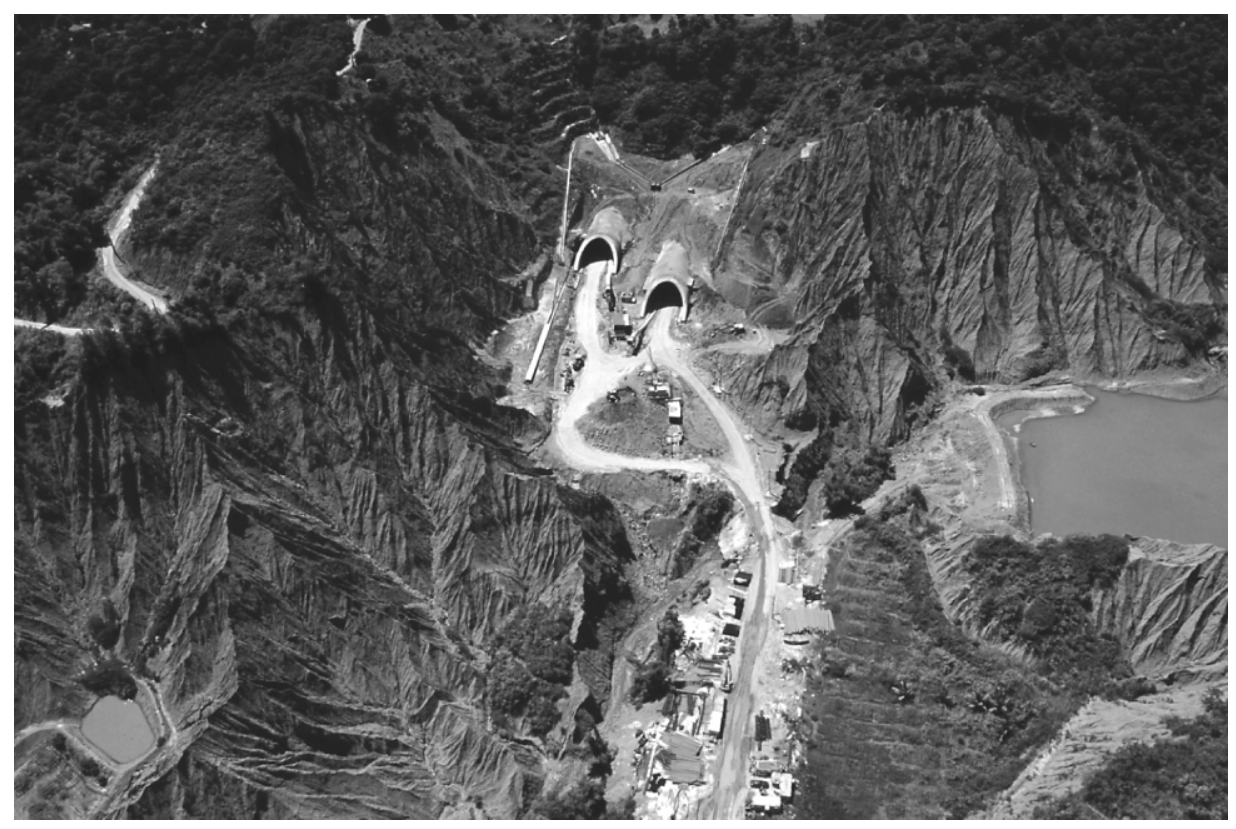

Fig. 2. A typical outcrop of mudstone slope taken from the northern portal of Chungliao Tunnel in southwestern Taiwan. 
Table 1

Basic information of tunnels in mudstone area

\begin{tabular}{|c|c|c|c|}
\hline Tunnel & $\begin{array}{l}\text { The pressure tunnel } \\
\text { of Wushantou } \\
\text { Reservoir }\end{array}$ & $\begin{array}{l}\text { Lantan } \\
\text { Tunnel }\end{array}$ & $\begin{array}{l}\text { Tsoumalai } \\
\text { Tunnel }\end{array}$ \\
\hline Width $\times$ height $\left(\mathrm{m}^{2}\right)$ & $4.9 \times 5.1$ & $16 \times 12$ & $12.3 \times 9.8$ \\
\hline Length (m) & 408 (mined section) & 1212 (NB) 1255 (SB) & 333 \\
\hline Overburden $(\mathrm{m})$ & 19-44 & $40-70$ & $10-45$ \\
\hline Purpose & Water supply & Highway tunnel & Highway tunnel \\
\hline Rock type & Alternation of mudstone and sandstone & Massive mudstone, alternation of mudstone and sandstone & Massive mudstone \\
\hline Groundwater & None to water ingress & None to water ingress & None \\
\hline Major support & Steel ribs and shotcrete & Bolts, lattice girder, steel fiber and shotcrete & Steel ribs and shotcrete \\
\hline Excavated sequence & Full face excavation, top heading & Side pilots, top heading & Side pilot, top heading \\
\hline State & Completed in 1996 & Completed in 2001 & Completed in 1998 \\
\hline
\end{tabular}




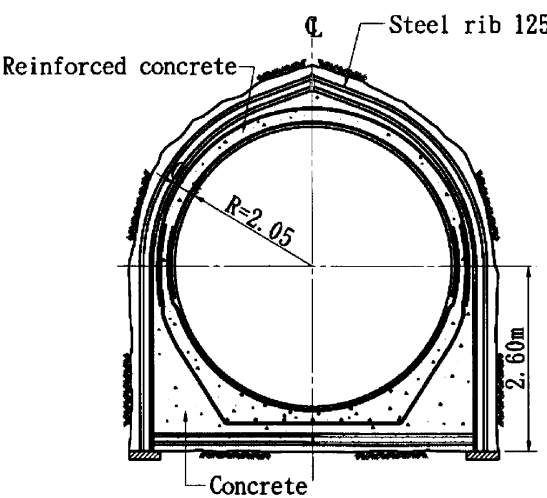

a. cross section

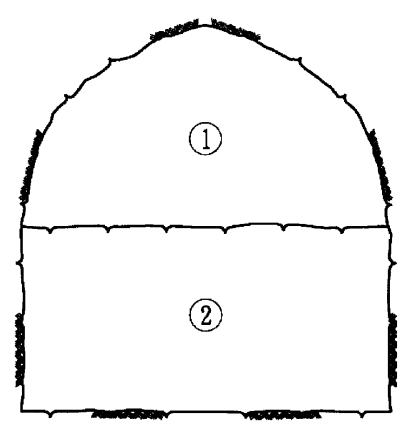

b. initial excavation

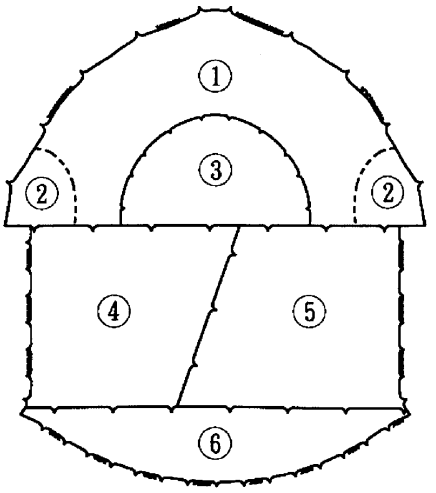

c. excavation sequence after $1^{\text {st }}$ hazard

Fig. 3. Cross-section and excavation sequence of the pressure tunnel of Wushantou Reservoir.

unfavorable geological and hydrological conditions for tunnelling.

\section{Case study in southwestern Taiwan}

Three tunnels, i.e. the pressure tunnel of Wushantou Reservoir, Lantan Tunnel and Tsoumalai Tunnel, have been constructed in the mudstone area in southwestern Taiwan during the 1990s (United Geotech Inc., 1997; Wang et al., 1997, 1998). The locations of these tunnels are displayed in Fig. 1. Table 1 summarizes the basic information of these tunnels. Moreover, Figs. 3-5 illustrate their cross-section and excavating sequence.

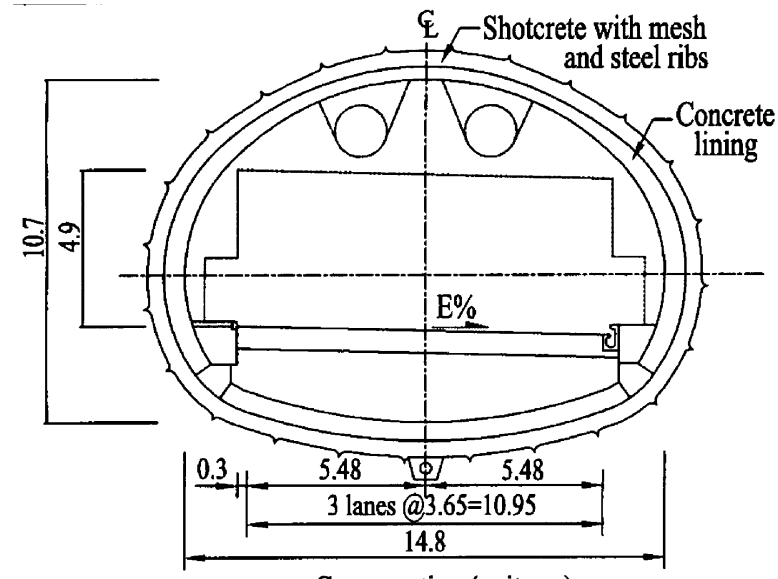

a. Cross section (unit : $\mathrm{m}$ )

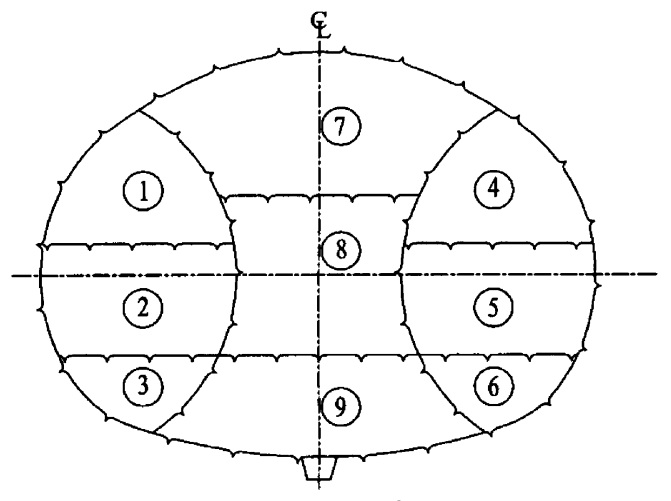

c. Excavation sequence for type II

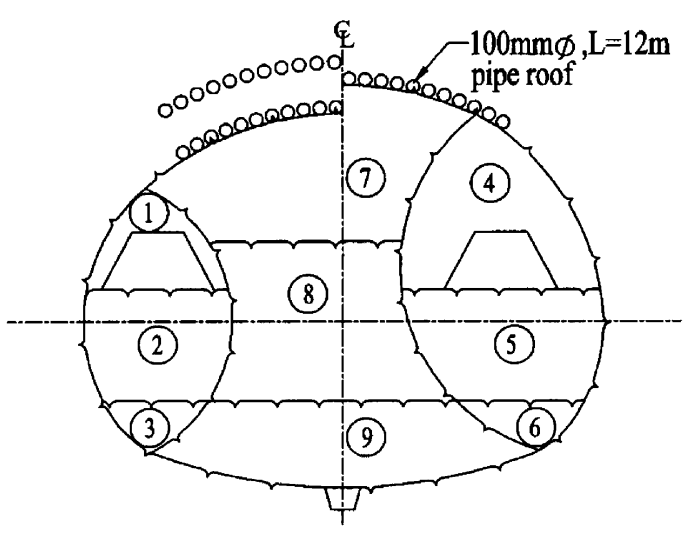

b. Excavation sequence for type I

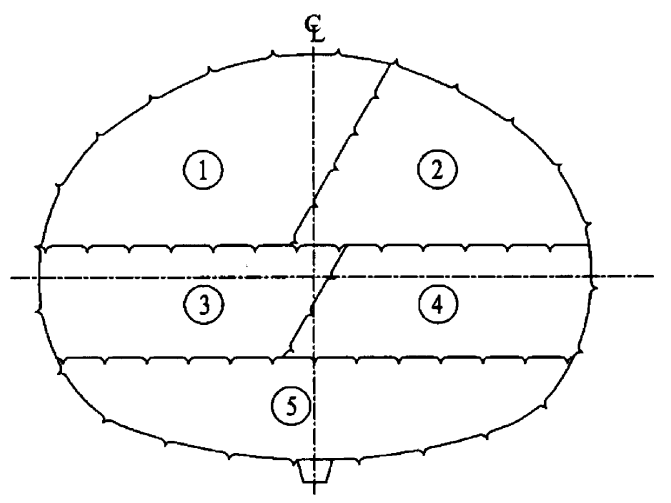

d. Excavation sequence for type III

Fig. 4. Cross-section and excavation sequence of Lantan Tunnel. 


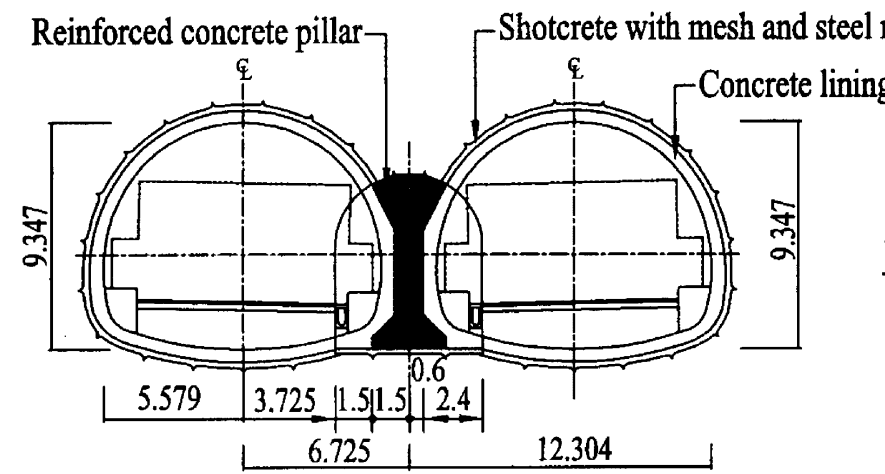

a. Cross section

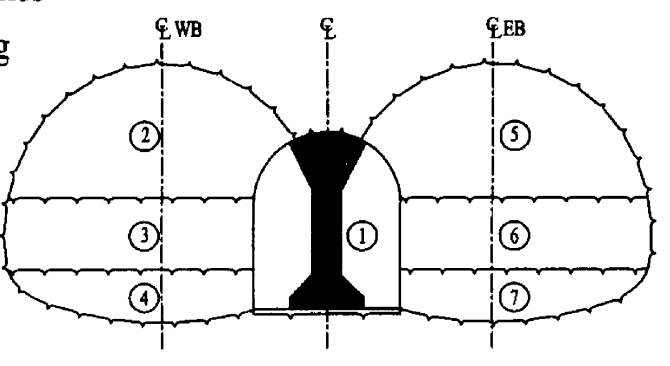

b. Excavation sequence

Fig. 5. Cross-section and excavation sequence of Tsoumalai Tunnel.

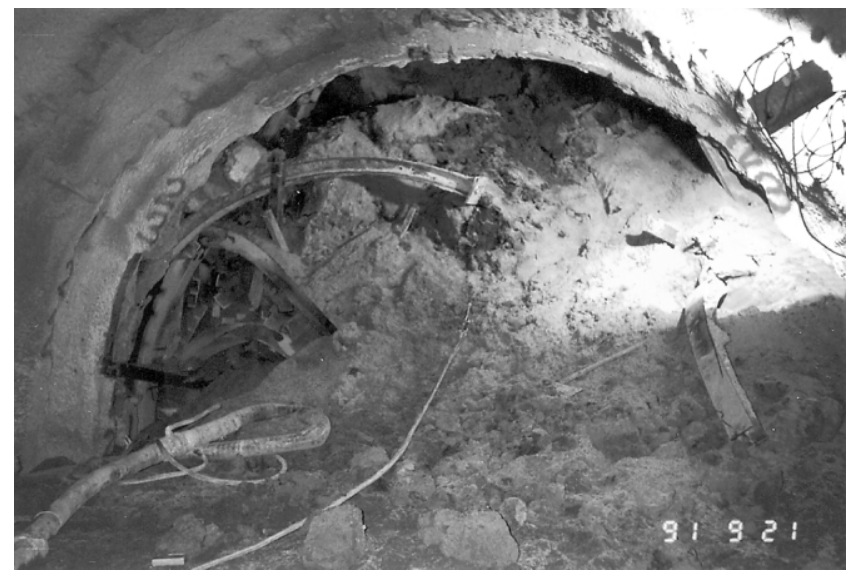

Fig. 6. The first collapse of the pressure tunnel of Wushantou Reservoir.

\subsection{The pressure tunnel of Wushantou Reservoir}

The pressure tunnel was constructed to renovate the water supply system of the Wushantou Reservoir. This tunnel passed through Liushuang Formation, which consists mainly of the alternation of mudstone and sandstone, and was driven against to the dip of the stratum. The high groundwater level in the dam-side section and the unfavorable attitude of bedding lead to an adverse condition for tunnelling.

At the beginning of tunnel construction the excavation and support scheme were determined by the geomechanics classification (Bieniawski, 1974). Rock mass rating (RMR) are evaluated based on six parameters, including the uniaxial compressive strength of the intact rock, drill core quality RQD, spacing, orientation and condition of joints, and ground water inflow. The site

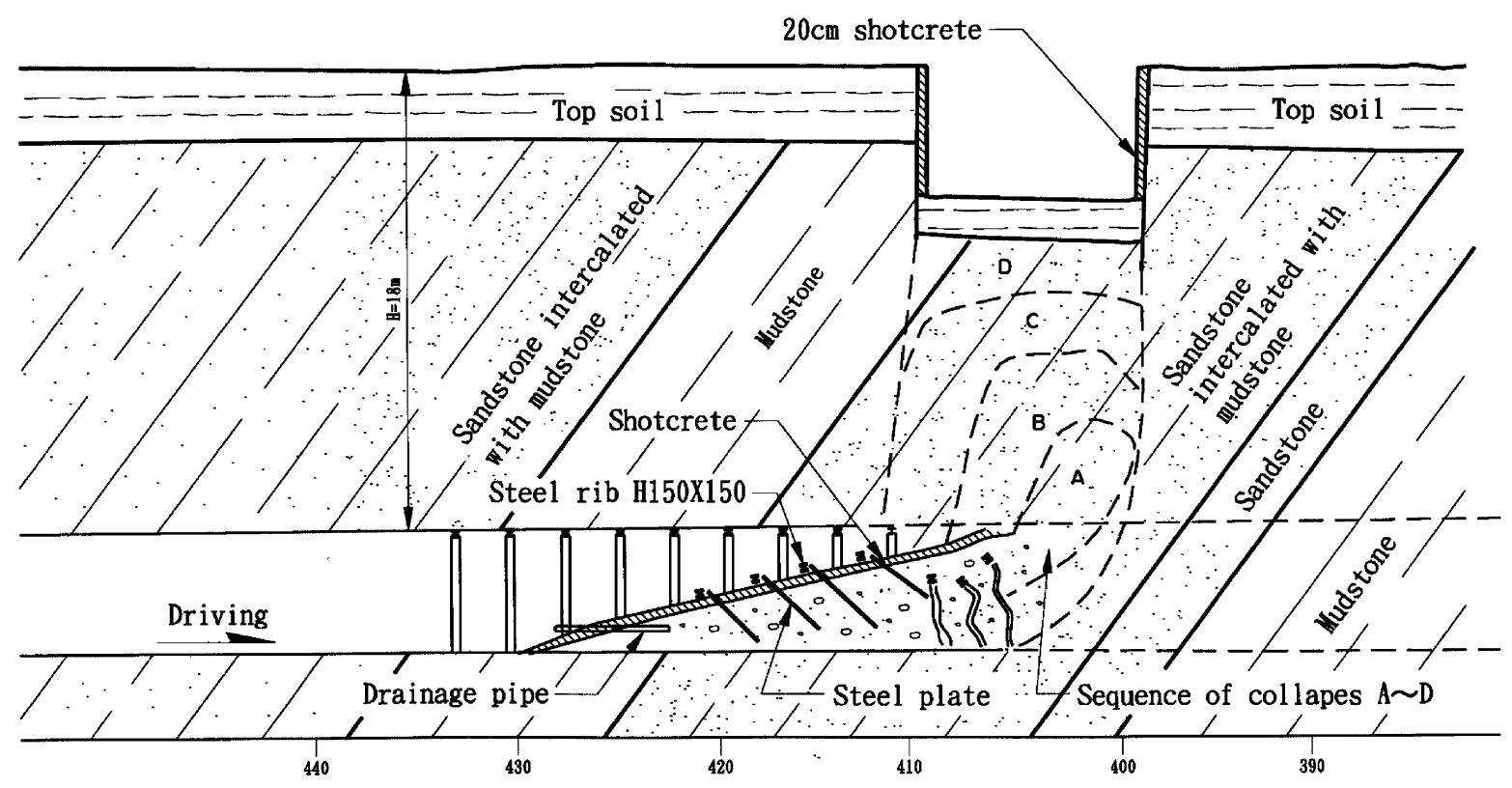

Fig. 7. Profile of the first hazard of the pressure tunnel of Wushantou Reservoir. 


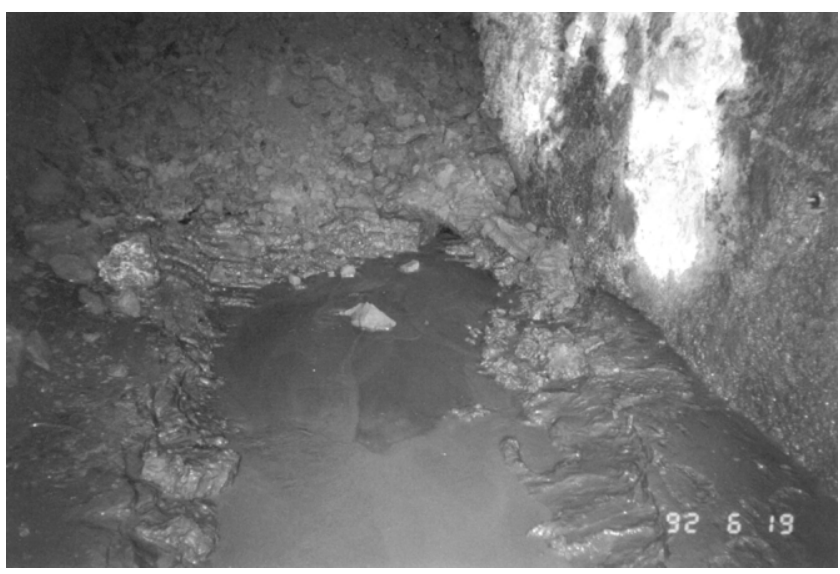

Fig. 8. Deteriorated mudstone beneath the working face of the pressure tunnel of Wushantou Reservoir.

experience revealed that this rating might not represent the engineering characteristic of surrounding rock properly due as poorly cemented rock and undeveloped discontinuities. The workability of the drilling tasks for grouting bolts was poor and the strength of bolts varied from 5.8 to $12.6 \mathrm{kN}$ (the lowest designed requirement is $10 \mathrm{kN}$ ). Hence, the rock bolts were not used in this tunnel. In addition, steel ribs and shotcrete with mesh (i.e. the heaviest support type of preliminary design) became the main support element in this tunnel. The top heading and benching method were adopted to excavate the tunnel in the beginning of tunnelling.

Two major hazards occurred during tunnelling. At the Sta. 0k +424 tunnel ran into a mudstone layer, occasionally alternation of mudstone and sandstone was encountered. Notably, the minor water inflow significantly shortened the stand-up time and deteriorated rock squeezed into the tunnel form the excavation face.
Drainage pipes were installed, forepolings by the $3 \mathrm{~m}$ long steel plates were adopted and tunnelling was continued. Until the Sta. 0k+406 tunnel ran into a 26 $\mathrm{m}$ thick formation composed of sandstone intercalated with mudstone. The sealing shotcrete with mesh were used to maintain the stability of excavation face; the forepolings by wooden and steel plate were also installed. Although these measurements could stabilize the tunnel, the instability occurred as soon as the excavating task started. Four cave-ins occurred in a week, finally induced a serious collapse approximately $1100 \mathrm{~m}^{3}$ in volume, as shown in Fig. 6. This hazard also extended to the ground surface $18 \mathrm{~m}$ above the tunnel and caused a cavity with $11 \mathrm{~m}$ in diameter and $6 \mathrm{~m}$ in depth. Fig. 7 illustrates the geological profile of this hazard. Thereafter, the three stage excavations by heading-benching-invert with ring cut as shown in Fig. $3 \mathrm{c}$ were applied to overcome this unfavorable geological condition. The $3 \mathrm{~m}$ long steel plates for forepoling and wing ribs for strengthening of foundation were used to reduce the deformation. To strengthen the stiffness of the tunnel support as soon as possible, the invert was installed in four rounds $(\sim 3 \mathrm{~m})$.

At Sta. 0k +275 tunnel had just passed through a mudstone layer and entered a weakly cemented sandstone. The heading stage had been completed in a mudstone layer. Drainage pipes covered by geosynthetics were installed because of the minor water inflow. However, the drainage measurements appeared to be ineffective and a serious mudflow occurred during the benching stage where tunnel just passed through the boundary of sandstone and mudstone. Huge water pressure destroyed the shotcrete sealing on excavation face and the sand grains were washed out. Piping phenomenon induced collapse of sandstone from the bottom of bench to the vault, subsequently causing continuous

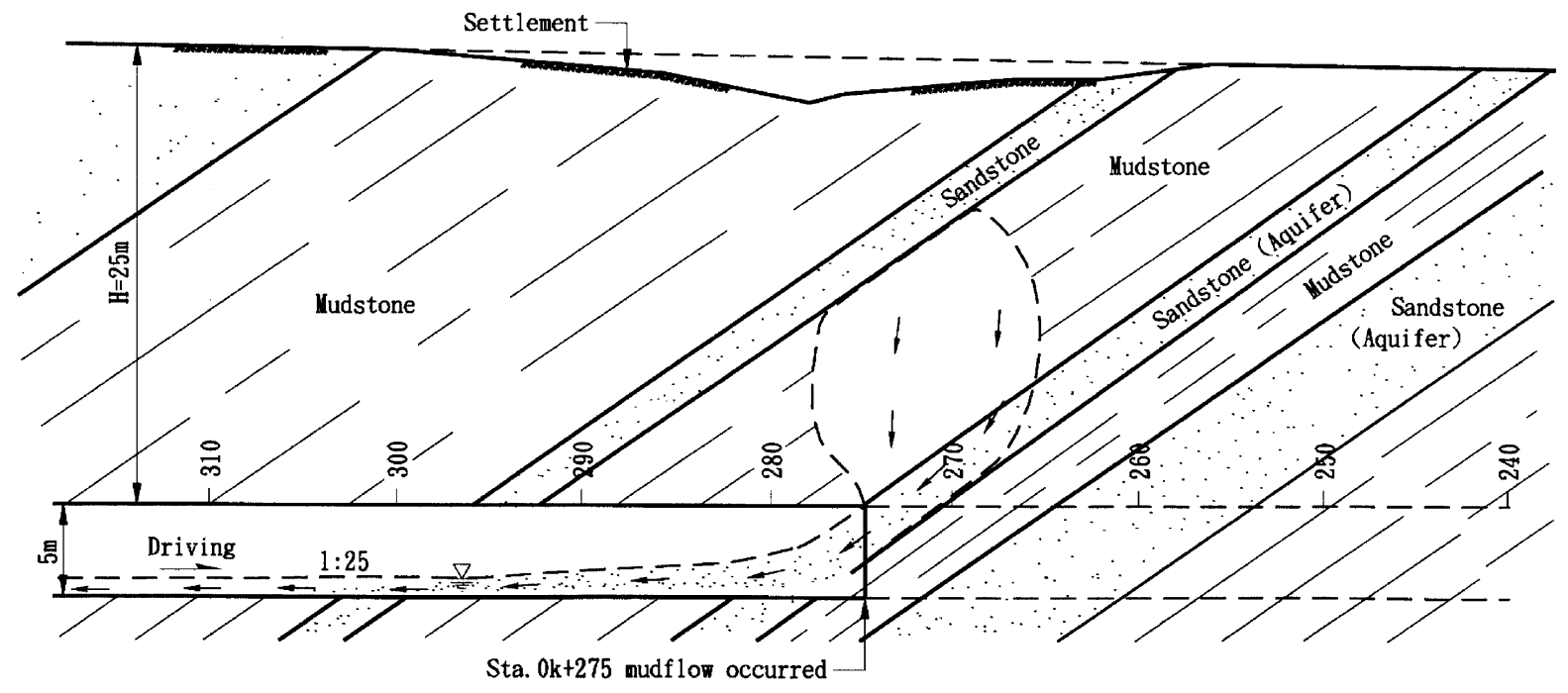

Fig. 9. Profile of the second hazard of the pressure tunnel of Wushantou Reservoir. 


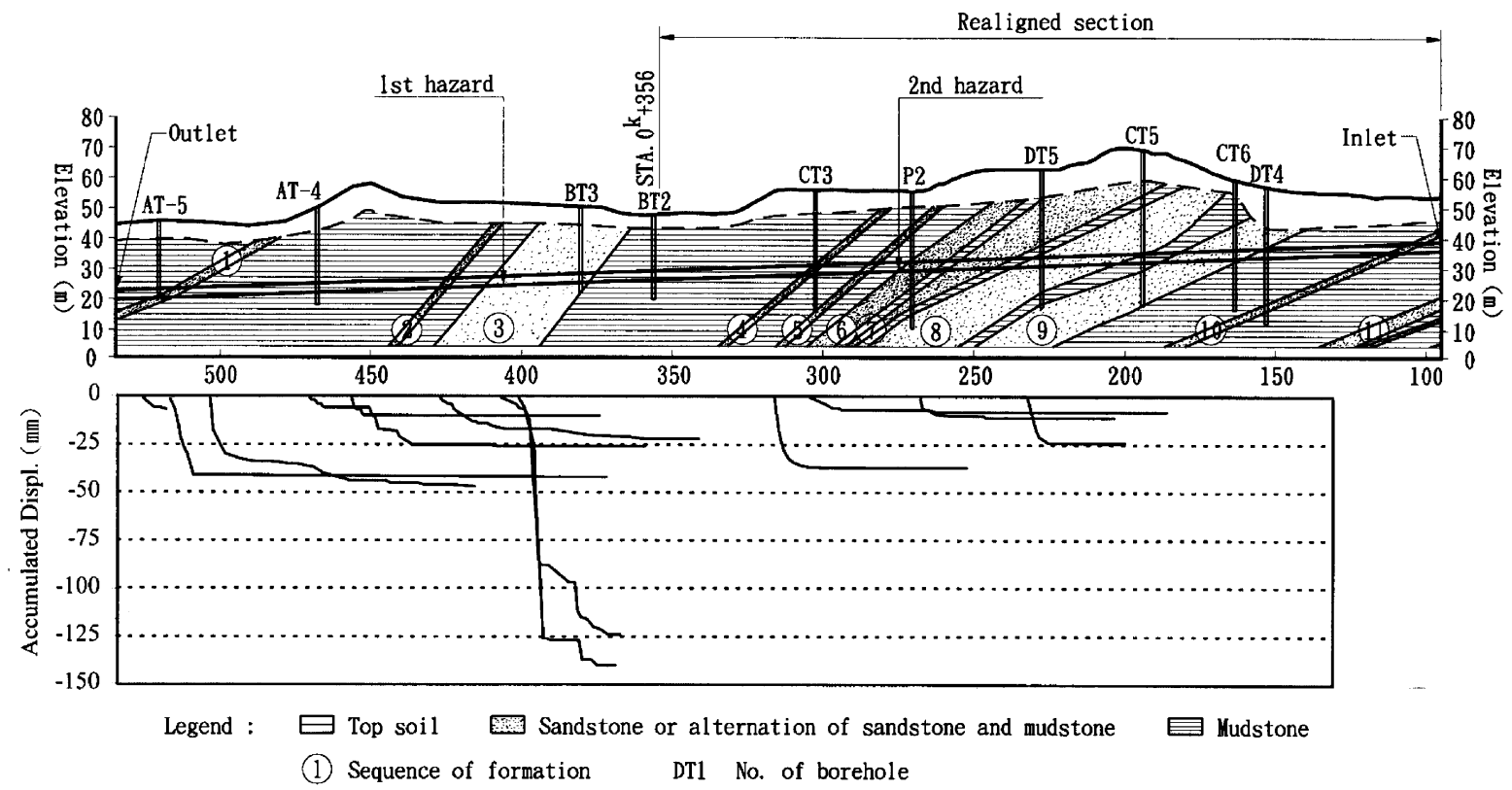

Fig. 10. The convergence monitoring result of the pressure tunnel of Wushantou Reservoir.

collapses of mudstone above sandstone. The collapsed mudstone slaked in a very short time. Fig. 8 illustrates the deteriorated mudstone beneath the working face a few hours before the collapse of the tunnel. In $6 \mathrm{~h}$, the tunnel was flooded by mudflow approximately $125 \mathrm{~m}$ in length, as shown in Fig. 9. This hazard also caused severe settlement on ground surface $26 \mathrm{~m}$ above the tunnel. Nearly $3000 \mathrm{~m}^{2}$ area was influenced and the maximum settlement reached $2.5 \mathrm{~m}$. Finally, the tunnel was ended by realignment. A pumping project from
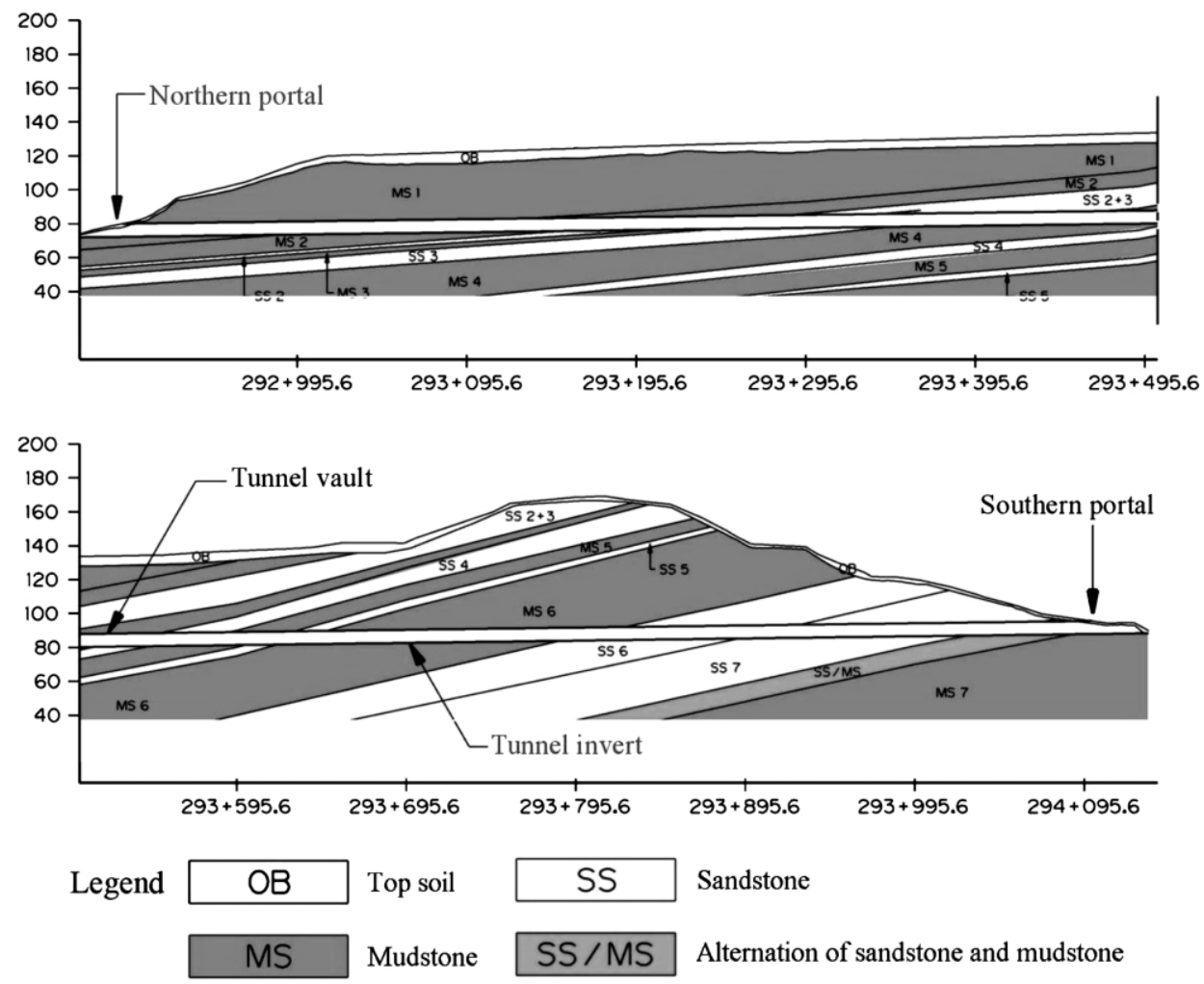

Fig. 11. The geological profile of Lantan Tunnel. 
ground surface was applied to drop down the groundwater table before the reconstruction of tunnel.

The monitoring data reveal that the groundwater and the relative position of sandstone and mudstone heavily influence the convergence of tunnel. Fig. 10 demonstrates the convergence monitoring results of this tunnel. According to this figure, the convergence in sandstone layer and mudstone in the vicinity of sandstone are twice as great or higher than in middle section of mudstone.

\subsection{Lantan Tunnel}

Lantan Tunnel includes double tubes three-lane tunnels. The tunnels pass through Liushuang Formation composed of mudstone, containing poorly cemented sandstone and their alternation. The strike of the Pleistocene sedimentary rocks ranges from $\mathrm{N} 5^{\circ}-30^{\circ} \mathrm{E}$, with dip $5-30^{\circ}$ to west. The groundwater level is approximately $10-20 \mathrm{~m}$ higher than the vault of the tunnel. Although the mudstone can be sought as impermeable layer, the permeability of sandstone is high as $2.0 \times 10^{-3} \mathrm{~cm} / \mathrm{s}$.

In the design stage of Lantan Tunnel, the characteristics of mudstone learned from the pressure tunnel of Wushantou Reservoir have been considered. Some tunnelling experiences with water inflow problem and their countermeasures e.g. the Pinglin tunnel (Tseng et al., 2001), have also been taken into account. A detailed survey by a large number of boreholes was also preformed to identify the thickness of mudstone and the relative position of mudstone and sandstone, as shown in Fig. 11. The groundwater level was surveyed as well. A pumping project from ground surface was performed to drop down the groundwater table before tunnelling. Three major excavation procedure and support classes are used according geological conditions. Table 2 presents the determination of the excavation procedure and the support type by the thickness of mudstone and its relative position with sandstone. Due as tunnelling behavior is highly affecting by the intercalated sandy

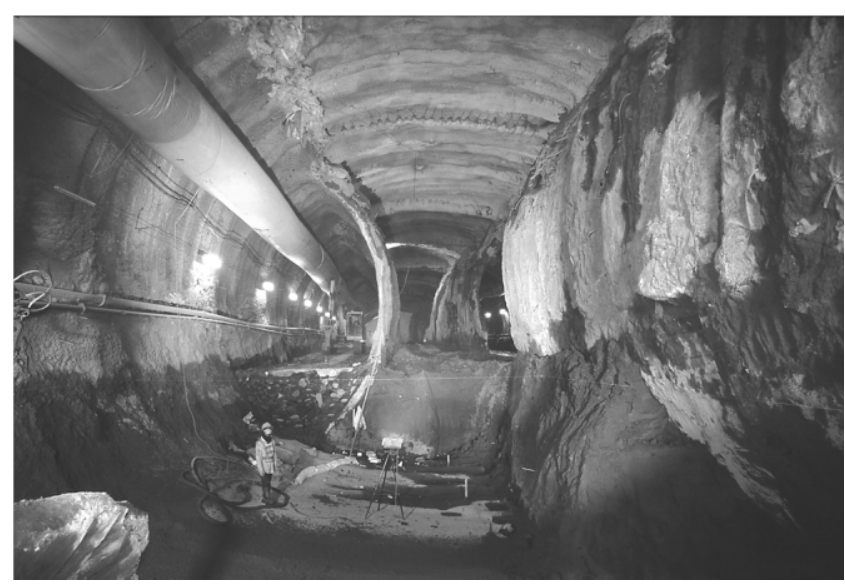

Fig. 12. The nine stages excavation process of Lantan Tunnel.

layer, a nine stages excavation strategy shown in Fig. 12 was implemented in case of the thickness of mudstone less than $50 \mathrm{~m}$. Similar excavation sequences with different forepoling methods were designed for alternation of sandstone and mudstone, and massive mudstone, respectively. The support strengths are also little different. Notably, the side pilots with $25-100 \mathrm{~m}$ drainage pipes were designed to drain the groundwater and reduce the settlement of tunnel.

The construction of Lantan Tunnel began in 1997, and holed through in May 2000. Among the $1.254 \mathrm{~km}$ (northern bound) excavation of tunnel, approximately $1070 \mathrm{~m}$ are excavated and supported by Type I and Type II of Table 2. The tunnelling experience reveals that the pumping measurement form ground surface can lower down the groundwater level to certain level but reduce the saturation of mudstone. The side pilots with auxiliary drainage pipes play an important role to reduce the deterioration of mudstone caused by ground water, and then the stability of excavation face can be well maintained.

The monitoring data show that under different ground conditions the settlements are limited in 29 and $13 \mathrm{~mm}$, and the horizontal convergence are limited in 36.0 and

Table 2

The determination of excavation and support of Lantan Tunnel

\begin{tabular}{|c|c|c|c|}
\hline $\begin{array}{l}\text { Excavation and } \\
\text { support type }\end{array}$ & $\mathrm{I}$ & II & III \\
\hline Advancing distance $(\mathrm{m})$ & $1.0-1.5$ & $1.0-1.5$ & $1.0-1.5$ \\
\hline Applied rock type & $\begin{array}{l}\text { Poorly cemented sandstone/sand, } \\
\text { alternation of sandstone and mudstone, } \\
\text { siltymudstone }\end{array}$ & Mudstone & Mudstone \\
\hline Applied situation & General condition & $\begin{array}{l}\text { The thickness of mudstone less } \\
\text { than } 50 \mathrm{~m}\end{array}$ & $\begin{array}{l}\text { The thickness of mudstone larger } \\
\text { than } 50 \mathrm{~m}\end{array}$ \\
\hline Excavation sequence & Side pilots & Side pilots & Top heading \\
\hline Main support element & $\begin{array}{l}\text { Steel fiber shotcrete, rock bolts and } \\
\text { lattice girder }\end{array}$ & $\begin{array}{l}\text { Steel fiber shotcrete, rock bolts and } \\
\text { lattice girder }\end{array}$ & $\begin{array}{l}\text { Steel fiber shotcrete, rock bolts and } \\
\text { lattice girder }\end{array}$ \\
\hline Auxiliary measurement & Pipe roof by large diameter steel pipe & Steel pipe & Steel pipe \\
\hline
\end{tabular}




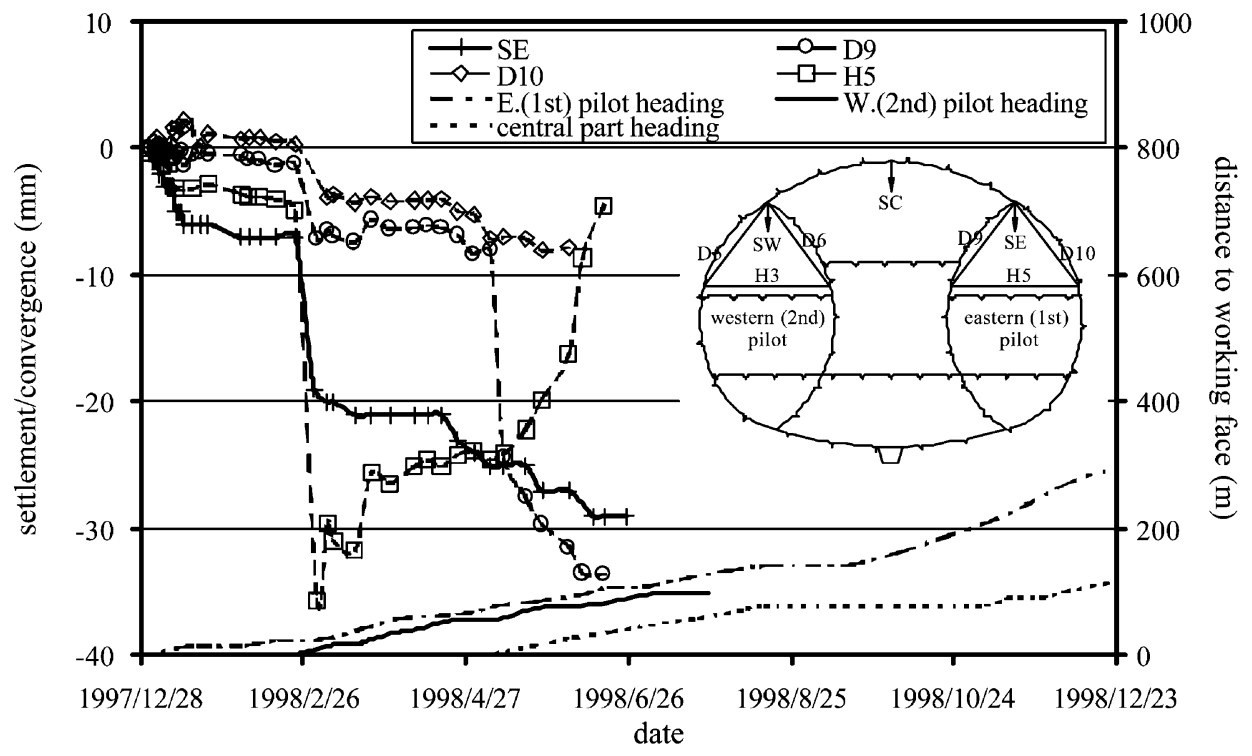

(a) Settlement and convergence (both presented in negative) of eastern (first) pilot

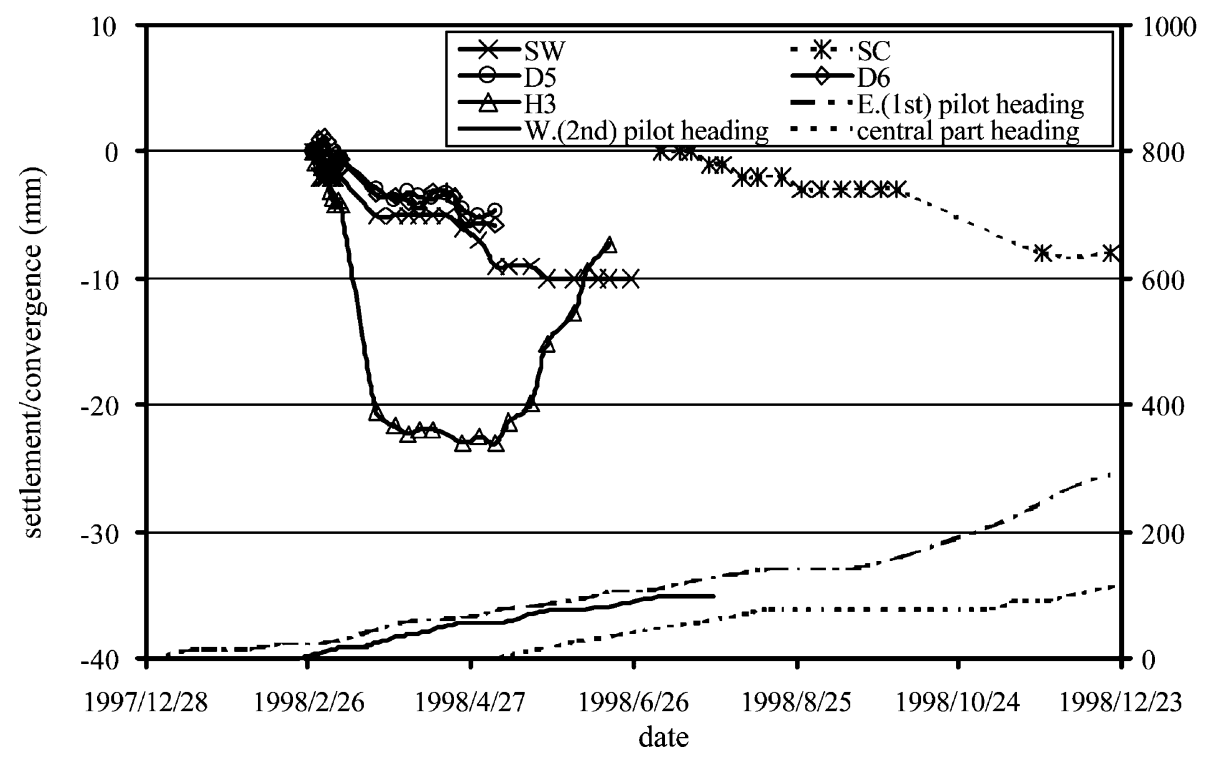

(b) Settlement and convergence of western (second) pilot and central part

Fig. 13. An illustration of monitoring results, Sta. $293+852$ of Lantan Tunnel.

$96.8 \mathrm{~mm}$ (which are 0.6 and $1.8 \%$ compared with their width of excavation) for the first side pilot and for second one, respectively (Continental Engineering Corp. 2000). A typical monitoring result for nine stages excavation section is illustrated in Fig. 13. Settlement and convergence curve exhibit complex characteristics due to interaction of sequence excavation. The moment the adjacent pilot excavated, both of the horizontal convergence of the eastern (first) pilot and the western (second) pilot turned around into extensive tendency. However, the deformation of surrounding is rather limited for such a big tunnel in soft ground. It is believed that the excavation and support determination criteria may be appropriate.

Nevertheless, the average advancing rate during nine stages excavation is rather poor to be $27 \mathrm{~m} /$ month. The excavation procedure therefore was modified from nine stages to be seven. Finally, a single side pilot with five 


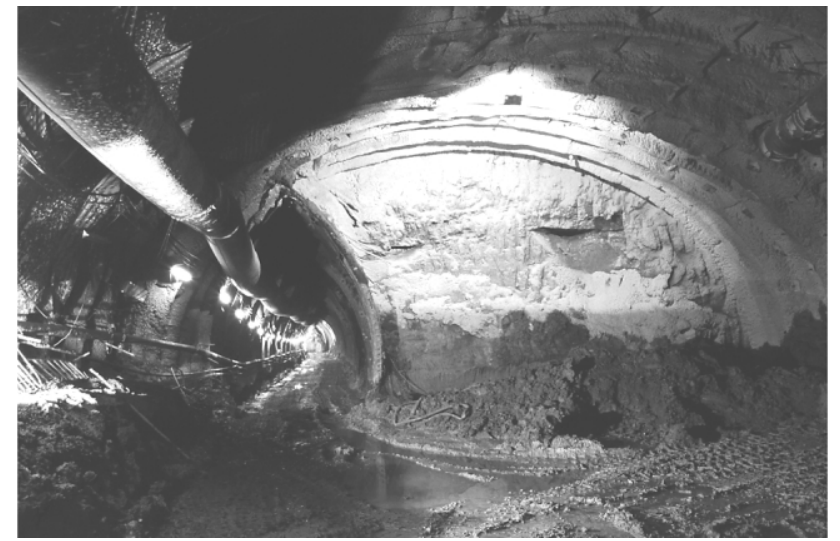

Fig. 14. The five stages excavation process used in Lantan Tunnel.

stages procedure was also adopted to drive the tunnel, as shown in Fig. 14. The advancing rate is rising to be approximately $60 \mathrm{~m} / \mathrm{month}$ in average. Fig. 15 illustrates the modification of excavation sequence of this tunnel in some detail.

\subsection{Tsoumalai Tunnel}

Tsoumalai Tunnel consists of two double-lane highway tunnels. Owing to the space limitation, these two tunnels were designed to co-construct and resemble a pair of glasses (Fig. 5). This design enlarged the width of excavation and inevitably increased the rock pressure applied on the support. Therefore, a special excavation scheme shown in Fig. 5 was adopted to reduce the disturbance on the rock in the vicinity of the tunnel.

The tunnel underwent a massive mudstone layer. Fortunately, no groundwater problem occurred. During tunnelling, the mudstone exhibited excellent self-sustained capacity and stand-up time, as shown in Fig. 16 taken from portal. Forepoling and shotcrete sealing were not necessary in this tunnel. The monitoring data indicated that the convergence of this tunnel was limited in a few millimeters to $1 \mathrm{~cm}$, and had stabilized in a couple rounds as the working face went ahead. The 333

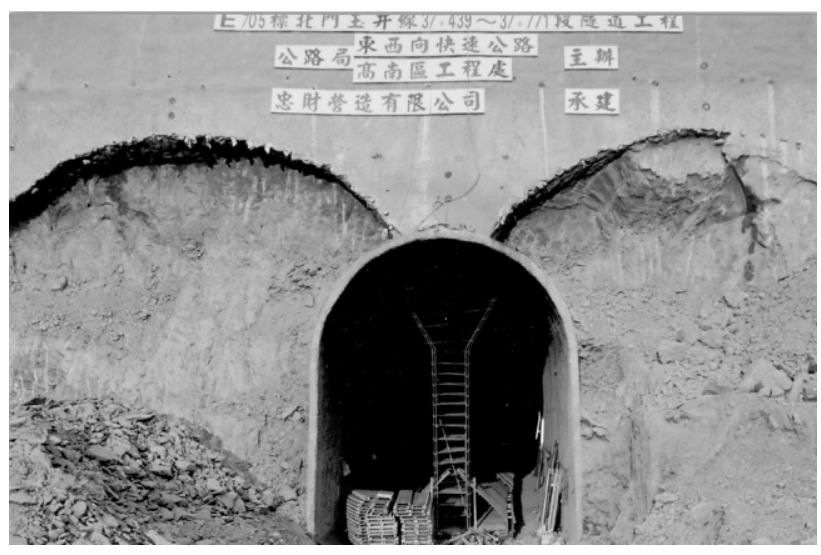

Fig. 16. Dry mudstone exposed in the portal of Tsoumalai Tunnel.

$\mathrm{m}$ long tunnel was completed earlier than the expected construction period by 4 months.

\section{Experience from mudstone tunnelling}

\subsection{The behavior of mudstone for tunnelling}

Experience from these three tunnelling indicate that the groundwater conditions largely control the engineering properties of mudstone surrounding a tunnel. Moreover, its deterioration phenomenon may heavily influence the stability of tunnel. The influence of water content on the mudstone behavior for tunnelling can be well understood by comparison of Figs. 6, 8, 14 and 16 .

Under a dry condition, the mudstone exhibits certain strength and moderate deformability. The mudstone is rather good to fair for tunnel excavation. The surrounding rock of tunnel exhibits the capacity of self-sustained and, usually, the stability of excavation face can be well maintained.

An increase of the water content causes the deterioration of mudstone to decrease its strength and increase its deformability. Although the excavation face may have a few hours stand-up time, the time dependent deformation occurs. The extra rock pressure may be

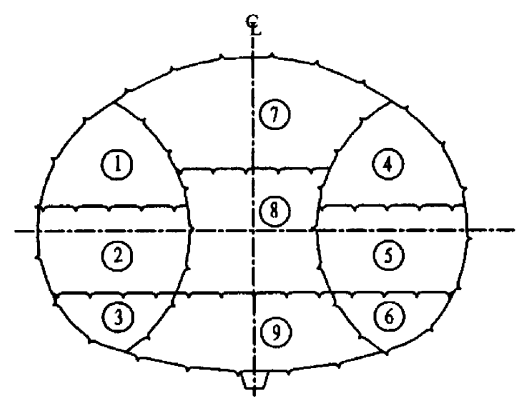

a. Excavation by 9 stages

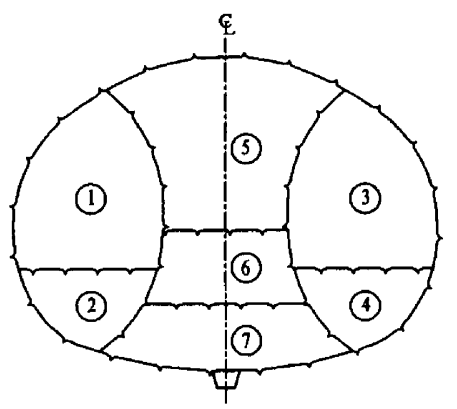

b. Excavation by 7 stages

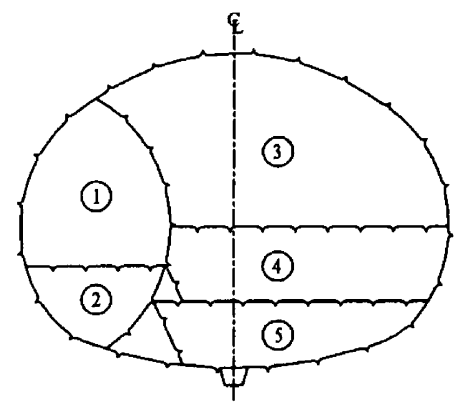

c. Excavation by 5 stages

Fig. 15. The modification of excavation sequence of Lantan Tunnel. 
induced due to the creep phenomenon. Under this circumstance, the deformation of tunnel should be controlled to minimize the zone of disturbance.

Under the circumstance that the aquifer exists, the mudstone may be thoroughly saturated, and the strength may loosen to residual level or even lower in case of large deformation occurred. Under this condition, the slaking phenomenon may occur after excavation and extra swelling pressure may apply on the support system of tunnel. Notably, piping phenomenon in aquifer and mudflow in mudstone should be prevented to avoid a serious hazard during tunnelling.

\subsection{Technical comments for mudstone tunnelling}

Determination of excavation and support should consider the possibility of deterioration of mudstone in site. Under the circumstance of mudstone tunnelling, the determination by the thickness of mudstone and its relative position to the nearby aquifer may be appropriate instead of the RMR or $Q$-value method which are widely used in Taiwan.

In mudstone area, if the groundwater level is higher than the vault of the tunnel, dewatering is one of the most important things in tunnelling. In order to drop down the groundwater, it is necessary to evaluate the effect of advanced drainage pipes, pumping well and drainage pilot regardless of whether inside or outside of the tunnel. Nevertheless, these auxiliary measurements may strongly release the water pressure in aquifer, but the water contained in mudstone is hardly reduced. Therefore, the forepoling with pipe roof by rebars, steel pipes, horizontal jet grouting or other measurements should be installed to protect the roof of the tunnel. In addition, shotcrete sealing or special excavation scheme such as ring cut should also be adopted to stabilize the excavation face. As the severe instability problem might cause the damages of tunnelling task, the ground improvement can also be performed.

To reduce the settlement of a tunnel, side pilot excavation method should be considered. The extra foundation such as wing ribs could be applied as well. Invert should be installed as soon as possible to strengthen the stiffness of the support. Under the condition of high swelling pressure, it is necessary to provided heavier support system.

Owing to the time dependent characteristic of mudstone in moisture condition, it is necessary to verify the effect of grouting bolts. Fig. 17 summarizes the results of pull out test of varies rock bolts used or tested in three tunnelling projects. The strengths of bolts installed by wash drilling method are significantly lower than which installed by dry-drilling. It is also clear that the strength exhibits high variation and reduces to $70-95 \%$ 1 month after installation compared to its initial strength (Liu et al., 1996; United Geotech Inc., 1997). Conse-

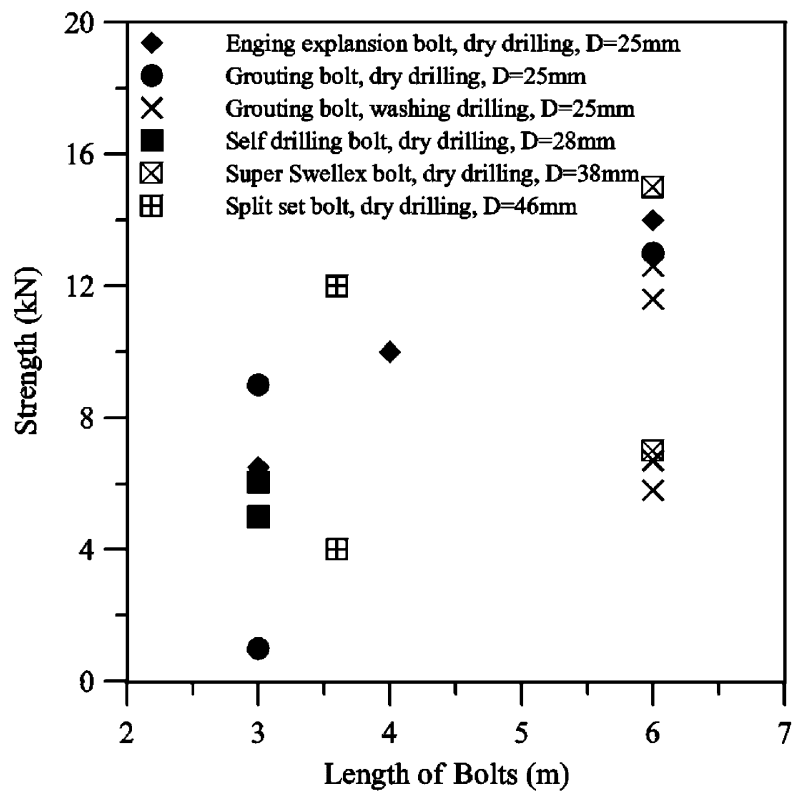

Fig. 17. The results of pull-out test of bolts installed in mudstone area.

quently, if rock bolts are determined to be one of the support elements, the designed strength should be reduced on the base of verification tests, and dry-drilling method should be adopted to avoid softening of the surrounding rock and collapsing of neighboring boreholes.

In addition to the general monitoring item, some particular features require close attention: the groundwater level and groundwater pressure, the deformation of excavation face and the heave phenomenon. Among which, it is very hard to do monitoring task on the deformation of excavation face, the monitoring on the volume of muck in each tunnelling round may be easier to alert the occurrence of plastic flow.

\section{Conclusions}

Owing to the behavior of mudstone affected strongly by water, preventing the deterioration of mudstone makes tunnelling in mudstone area is an undaunting task. From the three tunnelling cases presented herein, related experience indicates that the excavation sequence and support system should depend on the characteristic of mudstone, and its thickness and relative position to aquifer may indicate about that. Under the advanced dewatering, forepoling and adequate support, the deformation of surrounding rock may be reduced and the construction can be successful in mudstone tunnelling.

\section{Acknowledgments}

The authors would like to thank Mr Steven Wang, the geologist, Mr C.H. Chang, the manager of geotechn- 
ical division and Mr W.L. Wang, the vice president of United Geotech. Inc., for their kindly comments and revises on this paper. Figures 2, 12 and 14, photos by Mr B.L. Chi, are presented by courtesy of Taiwan Area National Expressway Engineering Bureau. The authors appreciate their generosity.

\section{References}

Bieniawski, Z.T., 1974. Geomechanics classification on rock masses and its application in tunnelling. Proceedings of the Third Congress International Society Rock Mech., Denver, vol. 2(A), pp. 27-32.

Continental Engineering Corp. 2000. Monitoring report of Lantan Tunnel. Taiwan Area National Expressway Engineering Bureau, Taipei.

Lee, D.H., Jhin, Y.Y., Tien, K.G., 1994. Characteristics of mudstone and the methods for slope protection. Sino-Geotechnics 48, 35-47.
Liu, H.S., Huang, C.J., Chen, Y.M., 1996. Study on characteristics of applying different types of rock bolts and prestressed anchors in sandstone and mudstone alternation. Sino-Geotechnics 55, 89-100.

Tasi, J.S., Chang, J.C., 1994. Mudstone's swelling slaking character and the surface protection for mudstone slope. Sino-Geotechnics 48, 95-105.

Tseng, D.J., Tsai, B.R., Chang, L.C., 2001. A case study on ground treatment for a rock tunnel with high groundwater ingression in Taiwan. Tunnelling and Underground Space Technology 16, $175-183$

United Geotech, Inc., 1997. Report on the monitoring system, geology and hydrology evaluation, the renovation of water supply system of Wushantou Reservoir. United Geotech, Inc., Taipei.

Wang, T.T., Chang, C.H., Wang, W.L., Huang, T.H., 1998. The tunnelling experience in a mudstone area in southwestern Taiwan. Regional Symposium on Sedimentary Rock Engineering, Taipei, pp. 197-202.

Wang, W.L., Su, J.J., Wu, F.F., 1997. The tunnel construction in the mudstone intercalated with sandstone stratum near the reservoir area. Sino-Geotechnics 59, 69-80. 